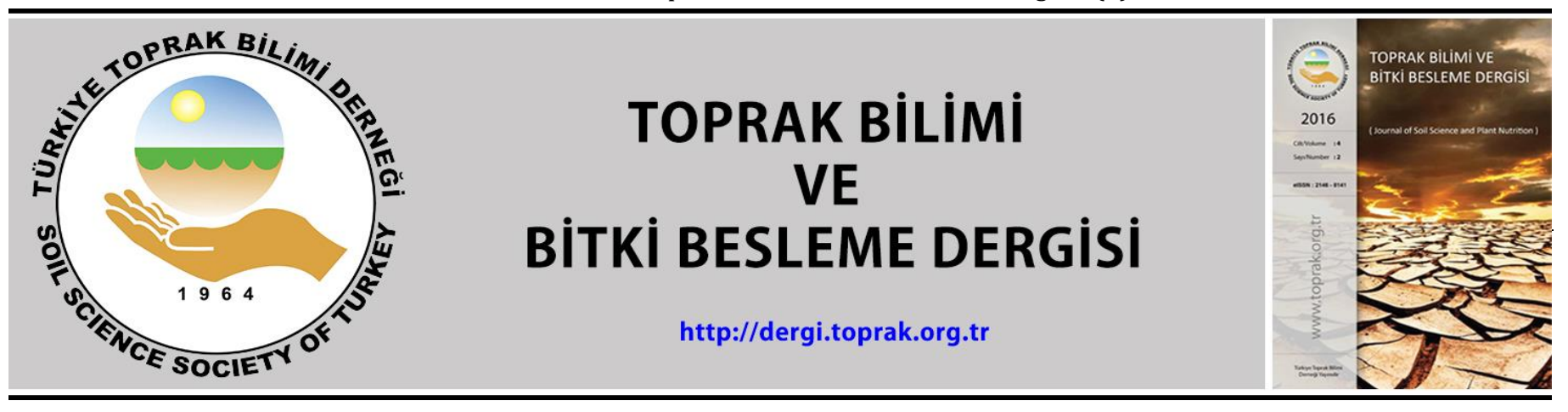

\title{
Kadmiyum ile kirli alanlarda bitki besin elementlerinin alınımı üzerine indol asetik asitin etkisi \#
}

\author{
Gizem Aksu * \\ Çanakkale Onsekiz Mart Üniversitesi Ziraat Fakültesi, Toprak Bilimi ve Bitki Besleme Bölümü, 17020 Çanakkale
}

\begin{abstract}
Özet
Bu çalışmada amaç; çeşitli nedenler sonucunda ortamlarda birikmiş olan kadmiyumun bitki tarafından alınmasını azaltmak amacı ile uygulanan indol asetik asitin, bitki besleme amacı ile verilen besin elementlerinin alımı ve birikimi üzerine etkisinin belirlenmesidir. Denemede materyal olarak; 5 kadmiyum dozu $(0,50,100,150,200 \mu \mathrm{M}$ Cd) ve 3 indol asetik asit dozu $(0 ; 1$ ve 10 $\mu \mathrm{M})$, ortam materyali olarak perlit ve bitki materyali olarak da marul kullanılmıștır. Bitkiler Hoagland besin solusyonu ile yetiştirilmiş, hasat edilmiştir. Hasattan sonra bitki örneklerinin yaş ve kuru ağırlığl, yaprak en, boy ve nem içeriği, fosfor (P), potasyum (K), magnezyum (Mg), kalsiyum (Ca), kükürt (S), demir (Fe), mangan (Mn) içerikleri belirlenmiştir. Denemeden elde dilen sonuçlara göre bitki yaş ve kuru ağırlığı 0 ve $50 \mu \mathrm{M}$ Cd olan ortamda artan IAA dozuna bağlı olarak artış göstermiş ancak Cd dozunun artmaya devam etmesi ile azalmıștır. İndole asetik asit uygulanmayan ortamda bitkilerin fosfor, kükürt ve potasyum içerikleri artan Cd dozları ile artış göstermiş ancak doz $200 \mu \mathrm{M}$ Cd çıktığında azalmıştır. Bitkilerin fosfor, kükürt ve potasyum içerikleri ortamda Cd konsantrasyonu artarken yapılan IAA uygulamaları ile artış göstermiştir, $200 \mu \mathrm{M}$ Cd olan ortamda $10 \mu \mathrm{M}$ IAA uygulamasında azalma olmuştur. Bitkilerin demir içeriği Cd birikimi olmayan ortamda $1 \mu \mathrm{M}$ IAA kullanımında artıș göstermiș IAA dozu $10 \mu \mathrm{M}$ olunca azalmıştır. Mangan içeriği ise Cd uygulanmayan ortamdaki bitkilere yapılan IAA uygulaması ile kontrole göre azalmıştır. Mangan içeriği 50 ve $100 \mu \mathrm{M}$ Cd uygulanmış ortamda demir içeriği ise 50, 100, $150 \mu \mathrm{M}$ Cd uygulanmış ortamda yapılan IAA uygulaması ile kontrole göre azalış göstermiştir.
\end{abstract}

Anahtar Kelimeler: Ağır metal, kirlilik, hormon, sebze.

The effect of indole acetic acid on nutrient uptake within cadmium accumulation zones \begin{abstract}
The objective of this study is to determine the effect of indole acetic acid (IAA), which is applied to reduce plant uptake of cadmium in accumulation zones, on the uptake and accumulation of plant nutrients. This research was conducted on lettuce plants with perlite as the medium, and treated with 5 doses of cadmium $(0,50,100,150,200 \mu \mathrm{M} C d)$ and 3 doses of IAA $(0,1,10 \mu \mathrm{M})$. The plants were grown with Hoagland Nutrition Solution and then harvested. After harvesting, the fresh and dry weight of the plants, leaf length, width and moisture content, phosphorus (P), potassium (K), magnesium ( $\mathrm{Mg}$ ), calcium (Ca), sulphur (S), iron (Fe) and manganese $(\mathrm{Mn})$ contents were determined. According to the results obtained from the experiment, the plant fresh and dry weight increased with an increasing dose of IAA at 0 and $50 \mu \mathrm{M} \mathrm{Cd}$, but decreased with a continued increase of Cd dose. Phosphorus, sulphur and potassium content of the plants increased with increasing doses of Cd but decreased when the dose was increased to $200 \mu \mathrm{M} \mathrm{Cd}$ in the medium with no application of indole acetic acid. Phosphorus, sulphur and potassium content of the plants increased with the IAA applications; however, as the Cd concentration increased in the medium, there was a decrease in the $10 \mu \mathrm{M}$ IAA application in the medium with $200 \mu \mathrm{M}$ Cd. The iron content of the plants increased with $1 \mu \mathrm{M}$ IAA in the absence of Cd accumulation, and decreased with IAA of $10 \mu \mathrm{M}$. The manganese content decreased with the IAA application to the plants in the absence of $\mathrm{Cd}$, when compared to the control. Manganese content decreased in the medium with applications of 50 and $100 \mu \mathrm{M} C d$ and iron content decreased with 50,100,150 $\mathrm{M}$ Cd, compared to the control with IAA application.
\end{abstract}

Keywords: Heavy metal, pollution, hormone, vegetable.

\section{Giriș}

(C) 2019 Türkiye Toprak Bilimi Derneği. Her Hakkı Saklıdır

Dünya nüfusu hızla artış gösterirken mevcut tarım arazileri azalmakta ve beslenme ihtiyacını karşılamak tüm dünyada sorun haline gelmektedir. Bilinçsiz, kontrolsüz ve yoğun uygulamalar neticesinde bazen beklenilen faydanın aksine, çevre kirlenmekte, kirlenen tarım topraklarının verim potansiyeli düşmektedir. Depolanması ve imhası zor olan atıklar ve yan ürünler su ve toprak kirliliği gibi çevresel problemlere neden

\footnotetext{
* Sorumlu yazar:

\# Bu çalışma 5. Uluslararası Katılımlı Toprak ve Su Kaynakları Kongresinde (Kırklareli, 2017) sunulmuştur Tel. : 02862180018

E-posta : gizemaksu@comu.edu.tr

Geliş Tarihi : 8 Şubat 2018

Kabul Tarihi $\quad$ : 10 Eylül 2019

2146-8141

$10.33409 /$ tbbbd.668605
} 
olabilmektedir (İlay ve ark., 2013). Topraklarda ağır metal birikimi mikroorganizmaları, bitkileri, hayvanları ve insanları olumsuz etkilemesinden dolayı potansiyel tehlike olarak görülmekte ve bu konudaki endișeler artmaktadır. Giderek artan bu soruna çözüm bulmak için yapılan çalışmalar yoğunlaşmaktadır.

Bitkisel üretimi sınırlandıran önemli stres etmenlerinden biri kirlenen çevre ile birlikte büyük bir sorun haline gelen ağır metallerdir. Son yıllarda kullanılan kimyasal gübreler, toprak düzenleyiciler, pestisitler, arıtma çamurları ve atık suların kullanımı topraklarda kirliliğe neden olmaktadır (Khan ve ark., 2007). Bunun yanında endüstriyel faaliyetler, motorlu taşıtların egzoz gazları, maden yatakları ve işletmeleri, volkanik faaliyetler, gibi pek çok etken ağır metal kirliliğinin nedenleri arasında yer almaktadır (Zengin ve Munzuroğlu, 2003).

Kadmiyum bitkisel üretimi sınırlandıran ve insan sağlı̆̆ını tehdit eden ağır metallerden biridir. Topraklarda Cd kaynağı ağır metallerce zengin ana materyal olabildiği gibi Cd topraklara; insan kaynaklı olarak atmosfer yoluyla, kanalizasyon çamurunun uygulanmasıyla, gübre ve pestisit kullanımıyla da girebilmektedir. Farklı kaynaklardan topraklara ulaşan Cd bitki, hayvan ve insanların beslenmesinde mutlak gerekli bir element olmayıp bilinen biyolojik bir fonksiyonu bulunmamaktadır (Marschner, 2008). Yer kabuğunda ortalama 0,1$0,2 \mathrm{mg} \mathrm{kg}^{-1} \mathrm{Cd}$ bulunurken tarım topraklarında $3 \mathrm{mg} \mathrm{kg}^{-1}$ kadmiyuma izin verilmektedir (Alloway, 1995; Kabata-Pendias ve Mukherjee, 2007). Kadmiyum çoğunlukla endüstriyel işlemlerden ve fosforlu gübrelerden besin zincirine transfer olmaktadır (Sandalio ve ark., 2001). Kadmiyum diğer metallerden daha fazla suda çözünebilirliğe ve hareketliliğe sahip olduğu için bitki tarafından alınabilirliği de fazladır. Bu nedenden dolayı toprakta birikimi en tehlikeli ağır metaldir.

Bitkilerin büyüme ve gelişmelerini tamamlayabilmeleri için bazı iç ve dış faktörlerin rol oynaması gerekmektedir. Bitkide bunları düzenleyen temel iç faktörler kimyasal özelliktedir. Bitki bünyesinde oluşup, büyüme ve gelişmeyi düzenleyen bu kimyasallara hormonlar ya da fitohormonlar (bitki hormonları) adı verilmektedir. Bitki hormonlarının önemi 19. yy başlarında anlaşılmış, bu tarihten itibaren bunların tarımsal ürünlerdeki fonksiyonu araştırılmaya çalışılmıştır. Bitki hormonlarının bir kısmı bitki büyüme ve gelişmesini uyarıp hızlandırmaktadır. Stimülatör adı verilen bu gruba oksin, sitokinin ve giberellinler dahil olmaktadır. Bir kısmı ise büyüme ve gelişmeyi gerileten etkilere sahip olduklarından dolayı bunlara inhibitörler adı verilmekte, absisik asit ve etilen bu grupta bulunmaktadır (Öktüren ve Sönmez, 2005).

Oksinler bitkide fizyolojik işlemleri ve hücre içi işlemleri düzenleyen organik maddelerdir ve indol asetik asit (IAA) doğal olarak meydana gelen, en çok bulunan ve bitkideki düzenleyici fonksiyonları iyi bilinen bir oksindir (Wang ve ark., 2007). İndol asetik asit çeşitli streslere karşı bitkinin dayanıklılık mekanizmasına katkıda bulunmaktadır. Bitkilerde sinyal hormonu olarak IAA bitki büyümesini ve gelişmesini düzenlemekte, stres dayanıklılığında çok önemli bir fonksiyona sahip bulunmaktadır (Yang ve ark., 2011).

Bitki hormonları stres yönetiminde çok önemli olup oksinlerin çeşitli streslerin yoğunluğunu iyileştirdiği gözlemlenmiștir (Choudhary ve ark., 2010). Bitkinin ağır metale toleransını geliştiren hormonların dışarıdan uygulanması ile bitkide metal zararını azaltabildikleri belirtilmektedir (Tassi ve ark., 2008).

Yapılan çalışmalar doğrultusunda; hormonların bitkilerin girdiği ağır metal stresi üzerine; organik asitler ve karbonhidratların rizosfere salınıp ağır metal alınımının azaltılması, alınan ağır metallerin aminoasit, fitokelatin gibi moleküllerle kompleks yaparak hücre duvarları ve vakuol gibi metabolik yollardan uzak bölgelerde biriktirilmesi, antioksidan enzim aktivitelerinin ve antioksidan moleküllerinin miktarlarının artırılması, hücre membranlarının onarılması gibi mekanizmalarda etkili olduğu ve stresi hafiflettiği ortaya konmuştur (Kovacik ve ark., 2009; Belkhadi ve ark., 2010; Bashmakov ve ark., 2012).

İndol asetik asit yüksek oranda kadmiyum kirlenmesine uğramış olan alanlarda bitki tarafından kadmiyum alınımını durduramamakta daha yüksek dozlara çıkarıldığında ise bitkiye zarar vermektedir. İndol asetik asit uygulaması $\mathrm{Cd}$ varlığında bitkiyi koruyarak verimde artış sağlamakta ancak bu durum kökte kendini gösterememektedir. Kadmiyum ile kirli olmayan ortamlarda IAA uygulanmamış bitkilere göre IAA uygulanmış bitkilerde meydana gelen ağırlık azalması; IAA maddesinin diğer elementlerin alınımı da engellediği sonucuna varılmasına neden olmuştur (Yazıcı, 2014).

Türkiye'de glda tüketimi büyük ölçüde tahıl kökenli olmasına rağmen beslenmemizde yaprakları yenen sebzeler de önemli yer tutmaktadır. Salata (Lactuca sativa L.) grubu sebzeler yaprakları yenen sebzeler arasında en yaygın olandır. Kabata-Pendias ve Pendias (1999-2001)'a göre marulun Cd konsantrasyonu 29400 ppm arasında değişmektedir (Kabata-Pendias ve Mukherjee, 2007). Marul yüksek miktarda Cd biriktiren bitkilerden biri olarak kabul edilmektedir (Pais ve Jones, 2000). Dokularında $3 \mathrm{mg} \mathrm{kg}^{-1}$ miktarından fazla $\mathrm{Cd}$ içeren bitkileri düzenli olarak tüketen insanlarda kadmiyumun toksik etkileri görülmektedir (Alloway, 1995). 
Bu çalışma ile çeşitli nedenler sonucunda kadmiyum birikimi olan alanlarda bitkinin toksik bir madde ve kirletici olan kadmiyum elementinin alınımını sınırlandırmak için kullanılan indol asetik asitin, bitki besin elementlerinin alınımı ve birikimi üzerine etkisinin belirlenmesi amaçlanmıștır.

\section{Materyal ve Yöntem}

\section{Materyal}

Denemede bitki materyali olarak yüksek miktarda kadmiyum biriktirebilen marul bitkisi kullanılmış ve Yedikule 5701 çeşidi seçilmiştir. Deneme Çanakkale Onsekiz Mart Üniversitesi Terzioğlu Yerleşke'sinde bulunan Ziraat Fakültesi Toprak Bilimi ve Bitki Besleme Bölümü'ne ait olan plastik örtülü ısıtmasız serada yürütülmüștür.

Denemede ortam olarak; kimyasal yapısı kararlı nötr bir malzeme olan ve kimyasal reaksiyona girmeyen, havalanmayı sağlayan bünyesindeki gözenekler sayesinde filtrasyonu arttırarak buharlaşmayı ve sulama ihtiyacını azaltan, çözünebilir iyonların çok az olması sebebiyle tuz ve alkalilik açısından sorun yaratmayan, ısı izolasyon özelliği sebebiyle bitkilerin sıcaklık değişimlerinden etkilenmesini asgari seviyeye düşürebilen perlit tercih edilmiştir.

\section{Yöntem}

Deneme; kaynak olarak kadmiyum sülfat kullanılarak kadmiyumun 5 farklı dozu $(0,50,100,150,200 \mu \mathrm{M})$, indol asetik asidin 3 farklı dozu $(0,1,10 \mu \mathrm{M})$ ve 3 tekerrürlü olarak tesadüf blokları deneme desenine göre kurulmuştur. Bitkiler Hoagland Besin Solusyonu uygulanarak yetiştirilmiş, kontrol bitkiler göz önünde bulundurularak ticari olgunluğa eriştiği zaman hasat edilmiştir. Hoagland Besin Solusyonu reçetesindeki elementler Azot: 210; Fosfor: 31; Potasyum: 234; Magnezyum: 48; Kalsiyum: 200; Kükürt: 64; Demir: 2,5; Mangan: 0,5; Bor: 0,5; Bakır: 0,02; Çinko: 0,05; Molibden: 0,01 mg/L olarak laboratuvar koşullarında hazırlanmıştır (Hoagland ve Arnon, 1950).

Hasattan sonra bitki örneklerinin yaş ve kuru ağırlı̆̆l, yaprak eni ve boyu belirlenmiştir. Hasat işleminden sonra sabit ağırlığa kadar kurutulan bitki örnekleri ögütüldükten sonra 0,5 g alınarak nitrik asit ve hidrojen peroksit ile yaş yakma yapılmıştır Jones ve ark. (1991). Elde edilen süzüklerde fosfor (P), potasyum (K), magnezyum (Mg), kalsiyum (Ca), kükürt (S), demir (Fe), mangan (Mn) içerikleri Selçuk Üniversitesi, Ziraat Fakültesi, Toprak Gübre Besleme Araştırma Laboratuvarında ICP cihazında ölçülmüştür.

Denemeden elde edilen veriler MINITAB 17.0 istatistik paket programında tek yönlü varyans analizi (OneWay ANOVA) ile değerlendirilmiştir. İstatistiki açıdan konular arasında varyans analizi sonuçlarına göre önemli bulunan farklar LSD testi ile klyaslanmıştır.

\section{Bulgular ve Tartışma}

\section{Bitki yaş ve kuru ağırlı̆̆ı}

İndol asetik asit kullanımı sonucu elde edilen bitki yaş ve kuru ağırlıkları Çizelge 1'de verilmiştir. Bitki yaş ağırlıklarının artan Cd dozuna paralel olarak azalış göstermektedir. Bitki yaş ağırlığında meydana gelen bu değişim istatistiki anlamda önemlidir. Yapılan IAA uygulaması bitki yaş ağırlığında bir değişim meydana getirmemiştir. Bitki kuru ağırlıklarında da yaş ağırlığa benzer sonuçlar elde edilmiştir. Yapılan $\mathrm{Cd}$ uygulamaları bitki kuru ağırlığını istatistiksel olarak değiştirmiştir. Yapılan IAA uygulaması bitki kuru ağırlığında bir değişim meydana getirmemiştir. Elde ettiğimiz sonuçlar daha önce yapılan çalışmalar ile benzerlik göstermektedir (Belkhadi ve ark., 2010; Zhang ve ark., 2014).

Çizelge 1. Bitki yaş ve kuru ağırlığı (g)

\begin{tabular}{|c|c|c|c|c|c|c|c|c|c|c|}
\hline \multirow{8}{*}{ 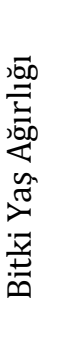 } & \multirow{2}{*}{$C d(\mu \mathrm{M})$} & \multicolumn{3}{|c|}{ IAA $(\mu \mathrm{M})$} & \multirow[b]{2}{*}{ Ort. } & \multirow{7}{*}{ 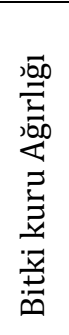 } & \multicolumn{3}{|c|}{ IAA $(\mu \mathrm{M})$} & \\
\hline & & 0 & 1 & 10 & & & 0 & 1 & 10 & Ort. \\
\hline & 0 & 64 & 67 & 73 & $68 \mathrm{~A}$ & & 4,72 & 5,82 & 6,49 & $5,68 \mathrm{~A}$ \\
\hline & 50 & 55 & 57 & 61 & $57 \mathrm{~B}$ & & 3,82 & 4,46 & 4,30 & 4,19 B \\
\hline & 100 & 46 & 43 & 49 & $46 \mathrm{C}$ & & 2,85 & 3,04 & 3,08 & $2,99 \mathrm{BC}$ \\
\hline & 150 & 45 & 35 & 36 & $39 \mathrm{C}$ & & 3,28 & 2,16 & 1,94 & $2,46 \mathrm{C}$ \\
\hline & 200 & 42 & 39 & 21 & $34 \mathrm{C}$ & & 3,17 & 2,24 & 1,54 & $2,32 \mathrm{C}$ \\
\hline & Ortalama & 50 & 48 & 48 & & & 3,57 & 3,54 & 3,47 & \\
\hline
\end{tabular}

${ }^{*}$ Büyük harfler ortalamaları göstermekte ve aynı harfler arasındaki fark önemli değildir. *: P $\leq 0,01$ göre önemli

\section{Bitki yaprak en ve boyu}

İndol asetik asit kullanımı sonucu elde edilen bitki yaprak eni ve boyu verileri incelendiğinde, bitki yaprak eninin artan Cd dozuna paralel olarak azalış gösterdiği görülmektedir (Çizelge 2). Bitki yaprak eninde 
meydana gelen bu değişim istatistiki anlamda önemlidir. Yapılan IAA uygulaması bitki yaprak eninde bir değișim meydana getirmemiștir. Bitki yaprak boyu ise artan Cd dozuna paralel olarak artış göstermiş ancak bu değişim istatistiki anlamda önemli bulunmamıştır. Yapılan IAA uygulaması bitki yaprak boyunda bir değişim meydana getirmemiştir. Elde ettiğimiz sonuçlar Zhang ve ark. (2014) yaptıkları çalışma ile aynı doğrultuda iken San-Francisco ve ark. (2005) yaptığı çalışma ile ters doğrultudadır.

Çizelge 2. Bitki yaprak eni ve boyu $(\mathrm{cm})$

\begin{tabular}{|c|c|c|c|c|c|c|c|c|c|c|}
\hline \multirow{7}{*}{ 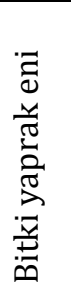 } & \multirow{2}{*}{$\mathrm{Cd}(\mu \mathrm{M})$} & \multicolumn{3}{|c|}{ IAA $(\mu \mathrm{M})$} & \multirow[b]{2}{*}{ Ort. } & \multirow{7}{*}{ 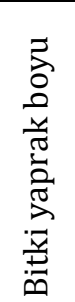 } & \multicolumn{3}{|c|}{ IAA $(\mu \mathrm{M})$} & \\
\hline & & 0 & 1 & 10 & & & 0 & 1 & 10 & Ort. \\
\hline & 0 & 8,33 & 8,83 & 9,83 & $9,00 \mathrm{~A}$ & & 18,50 & 16,50 & 18,00 & 17,66 \\
\hline & 50 & 8,16 & 8,50 & 9,33 & $8,66 \mathrm{~A}$ & & 18,50 & 19,16 & 19,33 & 19,00 \\
\hline & 100 & 7,83 & 8,00 & 7,50 & 7,77 AB & & 18,83 & 19,00 & 20,66 & 19,50 \\
\hline & 150 & 7,66 & 7,16 & 6,83 & $7,22 \mathrm{~B}$ & & 19,66 & 19,16 & 19,50 & 19,44 \\
\hline & 200 & 7,90 & 7,00 & 5,81 & $6,90 \mathrm{~B}$ & & 20,56 & 20,50 & 17,38 & 19,48 \\
\hline & Ortalama & 7,98 & 7,90 & 7,86 & & & 19,21 & 18,86 & 18,97 & \\
\hline
\end{tabular}

${ }^{*}$ Büyük harfler ortalamaları göstermekte ve aynı harfler arasındaki fark önemli değildir. *: P $\leq 0,01$ göre önemli

\section{Bitki yaprak nemi}

İndol asetik asit kullanımı sonucu elde edilen bitki yaprak nemi verileri incelendiğinde, bitki yaprak neminin artan Cd dozuna paralel olarak artış gösterdiği görülmektedir (Çizelge 3). Bitki yaprak neminde meydana gelen bu değişim istatistiki anlamda önemlidir. Yapılan IAA uygulaması bitki yaprak neminde bir değişim meydana getirmemiştir.

Çizelge 3. Bitki yaprak nemi (\%)

\begin{tabular}{ccccc}
\hline \multirow{2}{*}{$\mathrm{Cd}(\mu \mathrm{M})$} & 0 & 1 & IAA $(\mu \mathrm{M})$ & Ort. \\
\cline { 2 - 5 } & 92,76 & 91,31 & 91,24 & $91,77 \mathrm{~B}$ \\
50 & 93,03 & 92,23 & 92,94 & $92,73 \mathrm{AB}$ \\
100 & 93,92 & 93,65 & 93,73 & $93,77 \mathrm{~A}$ \\
150 & 93,69 & 93,83 & 94,35 & $93,96 \mathrm{~A}$ \\
200 & 92,83 & 94,21 & 93,84 & $93,63 \mathrm{~A}$ \\
\hline Ortalama & 93,24 & 93,04 & 93,22 &
\end{tabular}

${ }^{*}$ Büyük harfler ortalamaları göstermekte ve aynı harfler arasındaki fark önemli değildir. *: P $\leq$ 0,01 göre önemli

\section{Bitkinin makro element içerikleri}

İndol asetik asit kullanımı sonucu elde edilen bitki fosfor içerikleri Çizelge 4'de verilmiştir. Artan Cd dozları ile alınan P miktarının $150 \mu \mathrm{M}$ Cd uygulamasına kadar arttığı görülmektedir. Sonuçlarımız Benavides ve ark. (2005)'nın kadmiyumun suda yüksek bir çözünürlüğe sahip olduğu ve taşınırken su ile Ca, Mg, K, P gibi bazı elementleri kullandığını bu nedenden dolayı bu elementlerin bitkide arttığını açıkladıkları çalışma ile uyum içerisindedir. Çizelge incelendiğinde bitki fosfor değerlerinin uygulanan IAA konsantrasyonlarına bağlı olarak 4846 ile 5309 arasında değiştiği, bu farklar arasında istatistiki anlamda bir farklılık olmadığı görülmektedir.

Çizelge 4. Bitki fosfor içerikleri (mg kg-1)

\begin{tabular}{ccccc}
\hline \multirow{2}{*}{$C d(\mu \mathrm{M})$} & \multicolumn{4}{c}{ IAA $(\mu \mathrm{M})$} \\
\cline { 2 - 5 } & 0 & 1 & 10 & Ort. \\
\hline 0 & 4148 & 3627 & 3279 & $3684 \mathrm{~B}$ \\
10 & 4114 & 3856 & 4484 & $4151 \mathrm{~B}$ \\
150 & 6170 & 5293 & 5010 & $5491 \mathrm{~A}$ \\
200 & 6833 & 5515 & 6681 & $6343 \mathrm{~A}$ \\
\hline Ortalama & 5282 & 5938 & 5736 & $5652 \mathrm{~A}$ \\
\hline
\end{tabular}

${ }^{*}$ Büyük harfler ortalamaları göstermekte ve aynı harfler arasındaki fark önemli değildir. *: P $\leq 0,01$ göre önemli

İndol asetik asit kullanımı sonucu elde edilen bitki potasyum içerikleri Çizelge 5'de verilmiştir. Benavides ve ark. (2005)' nın çalışmalarına paralel olarak K miktarında 150 M Cd uygulamasına kadar artış görülmüştür. Kadmiyum uygulaması ile meydana gelen bu değişim istatistiksel olarak önemli bulunmuştur. Çizelge 7 incelendiğinde, farklı Cd birikimi olan ortamda, bitki potasyum değerleri arasında, IAA kullanımına bağlı olarak bir farklılık olmadı̆̆ı görülmektedir. 
Çizelge 5. Bitki potasyum içerikleri (mg kg-1)

\begin{tabular}{ccccc}
\hline \multirow{2}{*}{$\mathrm{Cd}(\mu \mathrm{M})$} & \multicolumn{4}{c}{ IAA $(\mu \mathrm{M})$} \\
\cline { 2 - 5 } & 0 & 1 & 10 & Ort. \\
\hline 0 & 16377 & 15171 & 14559 & $15369 \mathrm{~B}$ \\
50 & 16181 & 14898 & 16740 & $15940 \mathrm{~B}$ \\
100 & 20788 & 18845 & 18886 & $19506 \mathrm{~A}$ \\
150 & 20242 & 21809 & 23234 & $21762 \mathrm{~A}$ \\
200 & 19600 & 22513 & 20468 & $20860 \mathrm{~A}$ \\
\hline Ortalama & 18637 & 18647 & 18777 & \\
\hline
\end{tabular}

*Büyük harfler ortalamaları göstermekte ve aynı harfler arasındaki fark önemli değildir. * : P $\leq 0,01$ göre önemli

İndol asetik asit kullanımı sonucu elde edilen bitki magnezyum ve kalsiyum içerikleri Çizelge 6'da, kükürt içeriği ise Çizelge 7'de verilmiştir. Çizelge 7 incelendiğinde, farklı Cd birikimi olan ortamda, bitki kükürt değerlerinin $150 \mu \mathrm{M}$ Cd uygulamasına kadar artış gösterdiği görülmektedir. En yüksek kükürt içeriği $150 \mu \mathrm{M}$ Cd uygulamasının $0 \mu \mathrm{M}$ IAA uygulamasında belirlenirken en düşük içerik $0 \mu \mathrm{M}$ Cd uygulamasının $10 \mu \mathrm{M}$ IAA uygulamasında elde edilmiştir. Kadmiyum uygulaması ile bitki kükürt içeriğinde meydana gelen değişim istatistiki anlamda farklılık meydana getirmektedir. Sonuçlarımız diğer araştırmacıların sonuçları ile paralellik göstermektedir (Yazıcı, 2014). Bitki kükürt değerleri yapılan IAA uygulaması ile azalış göstermiş ancak bu değişim istatistiki anlamda bir farklılık meydana getirmemiştir.

Çizelge 6. Bitki magnezyum ve kalsiyum içerikleri ( $\left.\mathrm{mg} \mathrm{kg}^{-1}\right)$

\begin{tabular}{|c|c|c|c|c|c|c|c|c|c|c|}
\hline \multirow{8}{*}{ 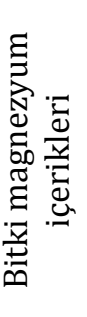 } & \multirow{2}{*}{$\mathrm{Cd}(\mu \mathrm{M})$} & \multicolumn{3}{|c|}{ IAA $(\mu \mathrm{M})$} & & \multirow{7}{*}{ 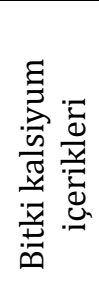 } & \multicolumn{3}{|c|}{ IAA $(\mu \mathrm{M})$} & \multirow[b]{2}{*}{ Ort. } \\
\hline & & 0 & 1 & 10 & Ort. & & 0 & 1 & 10 & \\
\hline & 0 & 1541 & 1529 & 1537 & 1536 & & 11136 & 10390 & 11584 & 11037 \\
\hline & 50 & 1528 & 1490 & 1532 & 1517 & & 11003 & 10329 & 11562 & 10965 \\
\hline & 100 & 1383 & 1552 & 1483 & 1473 & & 11748 & 12529 & 12500 & 12259 \\
\hline & 150 & 1545 & 1541 & 1563 & 1550 & & 12430 & 13588 & 13139 & 13052 \\
\hline & 200 & 1531 & 1562 & 1551 & 1548 & & 12488 & 13188 & 11722 & 12466 \\
\hline & Ortalama & 1506 & 1535 & 1533 & & & 11761 & 12005 & 12101 & \\
\hline
\end{tabular}

Çizelge 7. Bitki kükürt içerikleri $\left(\mathrm{mg} \mathrm{kg}^{-1}\right)$

\begin{tabular}{ccccc}
\hline \multirow{2}{*}{$\mathrm{Cd}(\mu \mathrm{M})$} & \multicolumn{4}{c}{ IAA $(\mu \mathrm{M})$} \\
\cline { 2 - 5 } & 0 & 1 & 10 & Ort. \\
\hline 0 & 2285 & 2060 & 1905 & $2083 \mathrm{C}$ \\
10 & 2311 & 2243 & 2594 & $2383 \mathrm{BC}$ \\
150 & 3368 & 2877 & 3020 & $3088 \mathrm{AB}$ \\
200 & 4029 & 3567 & 3460 & $3685 \mathrm{~A}$ \\
\hline Ortalama & 3322 & 3791 & 3187 & $3433 \mathrm{~A}$ \\
\hline
\end{tabular}

*Büyük harfler ortalamaları göstermekte ve aynı harfler arasındaki fark önemli değildir. *: P $\leq 0,01$ göre önemli

\section{Bitkinin mikro element içerikleri}

İndol asetik asit kullanımı sonucu elde edilen bitki demir ve mangan içerikleri incelendiğinde, bitki demir değerlerinin artan Cd dozuna paralel olarak azalış gösterdiği görülmektedir (Çizelge 8). Demir içeriğinde meydana gelen bu değişim istatistiki anlamda önemlidir. Bitki tarafından alınan demir miktarı yapılan IAA uygulaması ile azalmış istatistiki anlamda bir farklılık belirlenmemiștir. Farklı Cd birikimi olan ortamda, bitki mangan değerlerinin artan Cd dozu ile azalış gösterdiği görülmektedir. Bu değișim istatistiki anlamda farklılık meydana getirmemektedir. Bitki mangan değerleri yapılan IAA uygulaması ile azalış göstermiștir. Kontrol bitkileri ile kıyaslandığında $200 \mu \mathrm{M}$ Cd uygulamasında $10 \mu \mathrm{M}$ IAA mangan alımında \% 23 azalmaya neden olmuştur. Ancak bu değişim istatistiki anlamda bir farklılık meydana getirmemiştir.

Çizelge 8. Bitki demir ve mangan içerikleri $\left(\mathrm{mg} \mathrm{kg}^{-1}\right)$

\begin{tabular}{|c|c|c|c|c|c|c|c|c|c|c|}
\hline \multirow{8}{*}{ 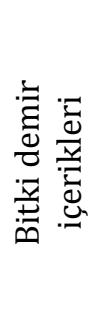 } & \multirow{2}{*}{$\mathrm{Cd}(\mu \mathrm{M})$} & \multicolumn{3}{|c|}{ IAA $(\mu \mathrm{M})$} & & \multirow{7}{*}{ 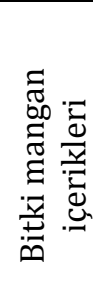 } & \multicolumn{3}{|c|}{ IAA $(\mu \mathrm{M})$} & \multirow[b]{2}{*}{ Ort. } \\
\hline & & 0 & 1 & 10 & Ort. & & 0 & 1 & 10 & \\
\hline & 0 & 136 & 142 & 99 & $126 \mathrm{~A}$ & & 47 & 40 & 43 & 43 \\
\hline & 50 & 199 & 78 & 98 & $125 \mathrm{~A}$ & & 38 & 32 & 35 & 35 \\
\hline & 100 & 122 & 109 & 103 & $111 \mathrm{AB}$ & & 43 & 40 & 39 & 41 \\
\hline & 150 & 110 & 53 & 69 & $77 \mathrm{BC}$ & & 33 & 35 & 44 & 38 \\
\hline & 200 & 57 & 72 & 87 & $72 \mathrm{C}$ & & 35 & 36 & 27 & 33 \\
\hline & Ortalama & 125 & 91 & 91 & & & 40 & 37 & 38 & \\
\hline
\end{tabular}

${ }^{*}$ Büyük harfler ortalamaları göstermekte ve aynı harfler arasındaki fark önemli değildir. *: P $\leq 0,01$ göre önemli 


\section{Sonuç}

Denemeden elde edilen verilere göre bitki de en fazla yaş ve kuru ağırlık kontrol dozunda elde edilirken en az ağırlık $200 \mu \mathrm{M}$ Cd dozunda belirlenmiş olup uygulanan kadmiyum dozları bitki yaş ve kuru ağırlığının önemli ölçüde azalmasına neden olmuştur. Uygulanan IAA dozu düzenli olmayan bir şekilde kök yaş ve kuru ağırlığını arttırmıştır bu artış rakamsal olarak elde edilmiş olmasına rağmen net verilere ulaşılamamıștır. Uygulanan kadmiyum dozları bitki boyunu artmasına neden olurken yaprak eninin azalmasına neden olmuştur. Yapılan Cd uygulamalarına bağlı olarak bitki tarafından alınan P, K, Mg, Ca, S artış gösterirken, Fe ve Mn'da azalma meydana gelmiştir. Kadmiyum ile kirli alanlarda yapılan IAA uygulaması sonucu K, Ca ve Mg alınımı artış gösterirken P, S, Fe ve Mn alımı azalmıştır.

Bu sonuçlara göre yüksek konsantrasyonlarda Cd bulunan ortamlarda yapılan IAA uygulamasının stresi hafiflettiğine dair kesin veriler ulaşlamamıştır. Kadmiyum kirliliğinin belirli limitlerde olduğu alanlarda marul yetiştirilmek durumunda kalındığında daha detaylı doz çalışmaları ile belirlenecek olan IAA dozları bitkinin kadmiyumdan etkilenmesini azaltmak için uygulanabileceği tespit edilmiştir.

\section{Kaynaklar}

Alloway BJ, 1995. Heavy Metal in Soils. Blackie Academic and Professional, New York.

Bashmakov DI, Pynenkova NA, Sazanova KA, Lukatkin AS, 2012. Effect of the Synthetic Growth Regulator Cytodef and Heavy Metals on Oxidative Status in Cucumber Plants. Russian Journal of Plant Physiology 59(1): 59-64.

Belkhadi A, Hediji H, Abbes Z, Nouairi I, Barhoumi Z, Zarrouk M, Chaibi W, Djebali W, 2010. Effects of Exogenous Salicylic Acid Pre-Treatment on Cadmium Toxicity and Leaf Lipid Content in Linum usitatissimum L. Ecotoxicology and Environmental Safety 73: 1004-1011.

Benavides MP, Gallego MS, Tomaro LM, 2005. Cadmium Toxicity in Plants. Brazilian Journal of Plant Physiology 17(1): 21-34.

Choudhary SP, Bhardwaj R, Guptac BD, Duttc P, Guptac RK, Biondi S, Kanwarb M, 2010. Epibrassinolide Induces Changes in Indole-3-Acetic Acid, Abscisic Acid and Polyamine Concentrations and Enhances Antioxidant Potential of Radish "Seedlings Under Copper Stress. Physiologia Plantarum 140: 280-296.

Hoagland DR, Arnon DI, 1950. The Water-Culture Method for Growing Plants without Soil. California Agricultural Experiment Station, Berkeley.

İlay R, Kavdır Y, Sümer A, 2013. The effect of olive oil solid waste application on soil properties and growth of sunflower (Helianthus annuus L.) and bean (Phaseolus vulgaris L.). International Biodeterioration \& Biodegradation 85: 254-259.

Jones JB, Wolf BJr, Mills AH, 1991. Plant Analysis Handbook. Micro-Macro Publishing, Inc., Georgia, USA.

Kabata-Pendias A, Mukherjee AB, 2007. Trace Elements from Soil to Human. Springer, Berlin, Germany.

Khan S, Cao Q, Zheng YM, Huang YZ, Zhu YG, 2007. Health risks of heavy metals in contaminated soils and food crops irrigated with wastewater in Beijing, China. Environmental Pollution 152: 686-692

Kovacik J, Gruz J, Hedbavny J, Klejdus B, Strnad M, 2009. Cadmium and Nickel Uptake are Differentially Modulated by Salicylic Acid in Matricaria chamomilla Plants. Journal Agriculture Food Chemistry 57: 9848-9855.

Marschner H, 2008. Mineral Nutrition of Higher Plants. Academic Press, Second Edition. London.

Öktüren F, Sönmez S, 2005. Bitki Besin Maddeleri ile Bazı Bitki Büyüme Düzenleyicileri (Hormonlar) Arasındaki İlişkiler. Derim 22 (2).

Pais I, Jones JBJr, 2000. The Handbook of Trace Elements. Published by St. Lucie Pres, Boca Raton, Florida.

Sandalio LM, Dalurzo HC, Gomez M, Romero-Puertas MC, del Rio LA, 2001. Cadmium-Induced Changes in the Growth and Oxidative Metabolism of Pea Plants. Journal of Experimental Botany 52 (364): 2115-2126.

San-Francisco S, Houdusse F, Angel M, Zamarren o Garnica M, Casanova E, Jose M, Mina G, 2005. Effects of IAA and IAA Precursors on The Development, Mineral Nutrition, IAA Content and Free Polyamine Content of Pepper Plants Cultivated in Hydroponic Conditions. Scientia Horticulturae 106: 38-52.

Tassi E, Pouget J, Petruzzelli G, Barbafieri M, 2008. The Effects of Exogenous Plant Growth Regulators in the Phytoextraction of Heavy Metals. Chemosphere 71: 66-73.

Wang H, Shan X, Wen B, Owens G, Fang J, Zhang S, 2007. Effect of Indole-3-Acetic Acid on Lead Accumulation in Maize (Zea Mays L.) Seedlings and the Relevant Antioxidant Response. Environmental and Experimental Botany 61: 246-253.

Yang Y, Wang QL, Geng MJ, Guo ZH, Zhao Z, 2011. Effect of Indole-3-Acetic Acid on Aluminum-Induced Efflux of Malic Acid from Wheat (Triticum aestivum L.). Plant and Soil 346: 215-230.

Yazıcı G, 2014. Kadmiyum birikimi üzerine marul (Lactuva sativa) bitkisinde indol asetik asidin etkisi. Yüksek Lisans Tezi, Çanakkale Onsekiz Mart Üniversitesi Fen Bilimleri Enstitüsü, Çanakkale.

Zengin KF, Munzuroğlu Ö, 2003. Fasulye fidelerinin (Phaseolus vulgaris L.) kök, gövde ve yaprak büyümesi üzerine kadmiyum $\left(\mathrm{Cd}^{++}\right)$ve Civa $\left(\mathrm{Hg}^{++}\right)^{\prime}$ nın Etkileri. C.Ü. Fen-Edebiyat Fakültesi Fen Bilimleri Dergisi, 24 (1).

Zhang X, Zhang X, Gao B, Li Z, Xia H, Li H, Li J, 2014. Effect of Cadmium on Growth, Photosynthesis, Mineral Nutrition and Metal Accumulation of an Energy Crop, King Grass (Pennisetum americanum x P. purpureum). Biomass and Bioenergy 67: 179-187. 